
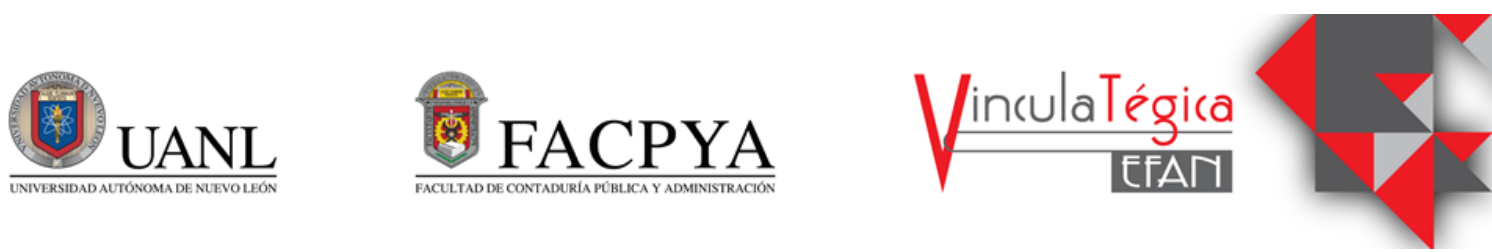

\title{
Understanding traceability: its relevance in the adoption of quality and safety measures across the supply chain
}

\author{
Alondra Yaneth de la Torre Dávila ${ }^{1}$, Francisco Javier Haro Navejas ${ }^{2}$ y Claudia M Prado \\ $\mathrm{Meza}^{3}$
}
${ }^{1}$ Universidad de Colima, Facultad de Economía, ade la torre0@ucol.mx, Josefa Ortiz de Domínguez No. 64 Col. La Haciendita, Villa de Álvarez, Colima, México (+52 312132 5589)
${ }^{2}$ Universidad de Colima, Facultad de Economía, Villa de Álvarez, Colima, México, fharo@ucol.mx, ${ }^{3}$ Universidad de Economía, Facultad de Economía, Villa de Álvarez, Colima, México, claudiaprado@ucol.mx,

Información del artículo revisado por pares

Fecha de aceptación: junio-2021

Fecha de publicación en línea: diciembre-2021

DOI: https://doi.org/10.29105/vtga7.1-167

\begin{abstract}
The article is based on a previous case study of a certified papaya producer from Colima which currently implements traceability in its operations. Traceability can be defined as an instrument to respond and avoid risks in the supply chain of a product. For Small and Medium Enterprises (SMEs) the use of traceability can be a competitive advantage, adding value to their products; or either an entry barrier to access to new international markets. The article analyzes the importance of traceability and the adoption of new practices to respond to future market requirements in a competitive globalized environment. Keywords: control, supply chain, traceability, transparency.

JEL Codes: D18, F52, M16
\end{abstract}

\section{INTRODUCTION}

For every company, ensuring quality and safety in their products is essential. For Small and Medium Enterprises (SMEs) the importance of improving efficiency on resources, saving costs, being competitive, and adopting a business model meeting those needs is indispensable to access to new markets. One way to achieve that is through the use of traceability, which can be defined as the ability of every actor in the supply chain, from producers to final consumers, to follow all the

\section{Resumen}

El artículo está basado en un estudio de caso previo de una productora de papaya certificada de Colima la cual implementa trazabilidad. La trazabilidad se puede definir como un instrumento para responder y evitar riesgos en la cadena de suministro de un producto. Para las Pequeñas y Medianas Empresas (PYMES) el uso de trazabilidad puede ser una ventaja competitiva, añadiendo valor a sus productos, o bien una barrera de entrada a nuevos mercados internacionales. El artículo analiza la importancia de la trazabilidad y la adopción de nuevas prácticas para responder a futuros requerimientos del mercado en un ambiente competitivo y globalizado.

Palabras clave: control, cadena de suministro, transparencia, trazabilidad.

Códigos JEL: D18, F52, M16

stages in the supply chain of a product, being able to deliver only safe and high-quality products to final consumers. Traceability allows the control and identification of every single phase in the manipulation of a product.

This article is based on the previous case study of a certified papaya producer from Tecomán, Colima, México. The company is dedicated to the production and commercialization of papaya in both the national and international markets, exporting 
the majority of the fruit into the United States of America (USA). The papaya producer currently implements traceability in its operations, complying with both international and national standards regarding the safety, hygiene, and quality of the fruit.

Traceability has been gaining more importance because of the constant demand for secured products in the market. Every day, more countries are enforcing new regulations regarding traceability mainly for the food industry, in order to guarantee the safety and avoid any kind of risk in customer health preventing possible disease outbreaks.

The article is organized as follows. It initiates with the literature review, where an evaluation of the circular economy model and its relationship with traceability is made. In addition, different traceability definitions are included and a general definition is presented to guide this paper. It further makes reference to the types and models of traceability. The section concludes by making reference to the international regulations enforced in the attempts to adopt traceability. The methods for the development of the article are shown in section three.

Subsequently, the results of the analysis are presented making an emphasis on the importance of traceability for organizations since it provides benefits beyond having traceable products. Traceability assists companies to develop key strategies between participants all along the supply chain; it helps to prevent possible errors by giving a fast and effective response; having transparency in every process it improves and creates new partnerships, and thus facilitates trade. To conclude the article, a brief analysis is made of the conducted research.

\section{LITERATURE REVIEW}

\subsection{Circular economy model}

As stated by the European Parliament (2015), a circular economy is a model of production and consumption, which involves sharing, leasing, reusing. repairing, refurbishing, and recycling existing materials and products as long as possible.

According to the same institution, the use of a circular economy benefits both organizations and consumers. Organizations can improve the security of the supply of raw materials, increase competitiveness, stimulate innovation, create new job opportunities, and increase economic growth; all these from a company's perspective.

On the other hand, the use of a circular economy model shares its benefits to customers too. Having more durable and innovative items that will help to increase and improve the quality of life, at the same time allows timesaving money in the long-term.

Traceability, along with the circular economy model are significant and emerging elements that can improve and completely change, for good, any company's activities in the entire supply chain. In other words, the use of a circular model along with traceability is about making decisions thinking about the long-term impact, rather than the short-term, transforming problems into new opportunities creating common value for the long-term period.

The combination of traceability together with a circular model helps companies to be more sustainable, being socially, but also environmentally responsible. Companies are able to be more efficient at the moment of manipulating resources, saving time and costs, and reaching new opportunities into new potential markets making and adapting reliable decisions.

\subsection{Traceability}

The need to be able to recall products identified as unsafe has become essential to 
protect people from foodborne diseases. Thus, traceability is a risk management tool that enables food businesses or authorities to respond to that need (International Trade Centre, 2015).

The Food and Agricultural Organization of the United States (FAO) objectives include eliminating food security by having more productive and sustainable processes. The FAO defines traceability as the ability to discern, identify and follow the movement of food or substance intended to be or expected to be incorporated into a food, through all the stages of production, processing, and distribution (2017, p.4).

The Organisation for Economic Cooperation and Development (OECD) main goal is to make policies to achieve equality, better opportunities, and well-being for all. The OECD shares the importance of traceability defining it as the process by which enterprises track materials and products and the conditions in which they were produced through the supply chain (OECD, 2017).

Analyzing and sharing the importance of traceability, for the purposes of this article, the following definition was made to be used to guide this paper. Traceability is the ability to collect information and monitor every phase in the supply chain. It allows actors involved to identify and give an answer to any possible risks or errors in a more effective and faster way.

\subsection{Types of traceability}

Traceability can be divided into three types depending on the product classification and its production process (Ekon, 2020).

1. Backward traceability: Makes reference to the origin of a product. Involves all the activities before the production process.

2. Internal traceability: Implicates all the processes performed in the production stage. It is related to the control a product must have inside the company.

3. Forward traceability: Includes the activities related to the logistics process. There must be an identification of the client and the product as well as the expiration and issued date, among other data.

However, complete traceability can not be possible without any of the three types of it; in other words, without backward traceability, it might not be possible to have forward traceability. Collected data from the very first phase is necessary to monitor the following stages. Each of the types is a complement of the previous one.

\subsection{Traceability models}

The use of a traceability model helps organizations to maintain consistency and accurately manipulate data collection along with all members in the supply chain. The Global Standards One (GS1) is a non-profit organization that develops global standards for businesses to facilitate and improve efficiency and safety in the supply chain; one of their main universally recognized standards is the GS1 barcode. According to the GS1, there are five main models of traceability:

1. One-up one-down model: It allows organizations to share the necessary information between their trading partners.

Figure 1. One-up one-down traceability model

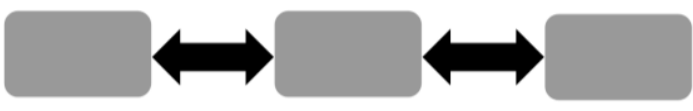

Source: Own elaboration based on data from GS1 (2017)

2. Traceability network model: Actors collect data in their own local system and stage it in a way that other actors can have access to it. In this model, control permission may vary. 
Figure 2. Traceability network model

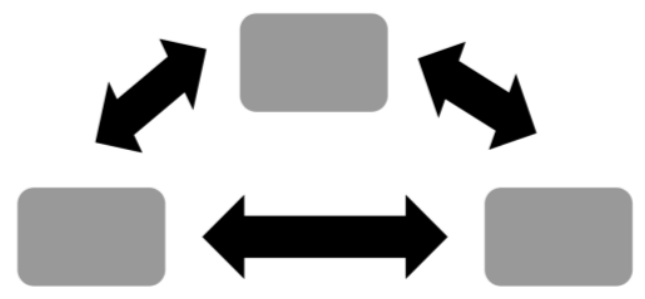

Source: Own elaboration based on data from GS1 (2017)

3. Centralized database model: Each trading partner makes data available to be shared in a central database.

Figure 3. Centralized database traceability model
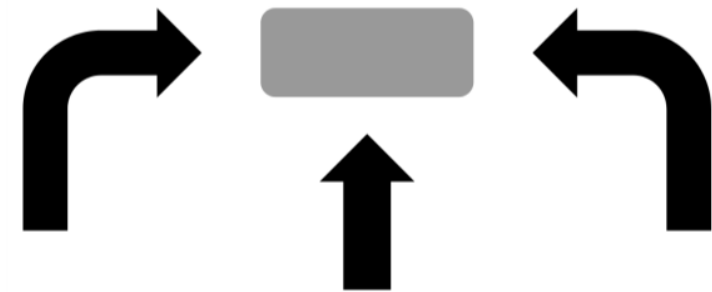

Source: Own elaboration based on data from GS1 (2017)

4. Cumulative tracking model: Push method which allows sharing of upstream data with parties further downstream, but can not be the other way around.

Figure 4. Cumulative tracking traceability model

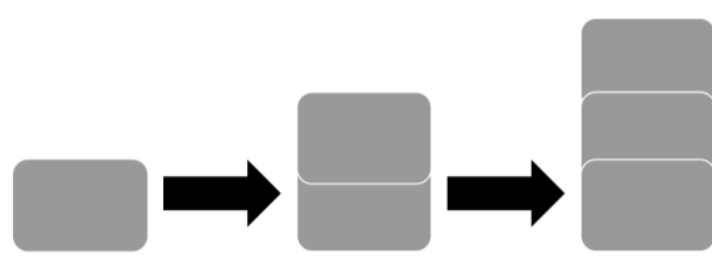

Source: Own elaboration based on data from GS1 (2017)

5. Decentralized and replicated model: A combination between the cumulative and networked models. In this model the data is enhanced and every participant in the supply chain is involved; participants also have a copy of all the data in their local network.

Figure 5. Decentralized and replicated modell

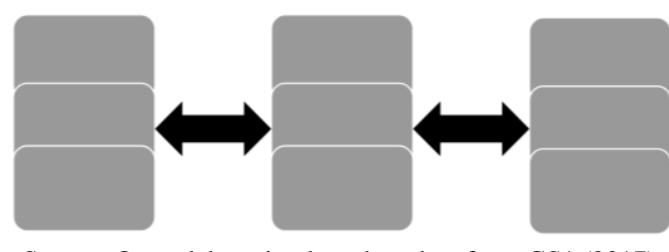

Source: Own elaboration based on data from GS1 (2017)

The use of a traceability model helps to organize and manipulate, in an appropriate manner, the data collection from actors across the supply chain. The selection of a traceability model depends on the operations of all the participants and the mutual collaboration between them. The adoption of a traceability model allows a fast, efficient, and effective response in the manipulation of a product in any type of situation.

\subsection{International traceability regulations}

According to GS1 (2015) having a standardized traceability system is essential for producers who want to export their products to the North American and European markets. Considering traceability has been gaining more relevance, different countries have been implementing legislation to regulate the use of traceability, with the main intention of preventing and even avoid, any type of disease outbreak that can directly affect customer's health.

\subsubsection{European Union}

Under the General Food Law Regulation EC, No 178/2002 food traceability is mandated in the European Union. The General Food Law establishes that on the Union market nothing more than safe products can be placed.

The general objective of the regulation includes guaranteeing high levels of protection for customers' health, the promotion of fair practices, and facilitating global trade. Article 13 of the law is about traceability; it states that traceability shall be established at all stages of a product, from production, processing, and distribution. 


\subsubsection{United States of America}

The Food and Drug Administration (FDA) Food Safety Modernization Act (FSMA) main objective is to focus on preventing any foodborne illness in the nation's food safety. Under FSMA, those importing food have the responsibility to ensure that their suppliers produce food complying with the United States' safety standards (FDA, 2016).

Recently, because of the most recent disease outbreak worldwide, COVID-19, a new rule to the FSMA was proposed to be included, this one related to the end-to-end food traceability across all the food industry as a preventive measure.

\subsubsection{Australia}

Food safety is governed by the Food Safety Act 1991 and regulated by the Food Standards Australia New Zealand (FSANZ). The 3.2.2 Food Safety Practices and General Requirements applies to all food businesses and food handlers in Australia.

There must be an inform among the food businesses about their health and hygiene obligations. The aforementioned standard specifies related to the receipt, storage,

Table 1. Main international regulations regarding traceability

\begin{tabular}{|c|c|c|c|}
\hline Institution & Regulation & Country & Year \\
\hline European Commission & $\begin{array}{l}\text { General Food Law EC No } \\
178 / 2002\end{array}$ & European Union & 2002 \\
\hline $\begin{array}{l}\text { Food and Drug Administration } \\
\text { (FDA) }\end{array}$ & $\begin{array}{l}\text { Food Safety Modernization Act } \\
\text { (FSMA) }\end{array}$ & United States & 2011 \\
\hline $\begin{array}{l}\text { Brazilian Association of } \\
\text { Supermarkets (ABRAS) }\end{array}$ & $\begin{array}{l}\text { Food Traceability and } \\
\text { Monitoring Program (RAMA) }\end{array}$ & Brazil & 2012 \\
\hline $\begin{array}{l}\text { Canadian Food Inspection } \\
\text { Agency }\end{array}$ & Safe Food for Canadians Act & Canadá & 2012 \\
\hline $\begin{array}{l}\text { Food Standards Australia New } \\
\text { Zealand (FSANZ) }\end{array}$ & $\begin{array}{l}\text { Standard 3.2.2 Food Safety } \\
\text { Practices and General } \\
\text { Requirements }\end{array}$ & Australia & 2014 \\
\hline
\end{tabular}

Source: Own elaboration processing, display, packaging, transportation, disposal, and recall of food.

\subsubsection{Canadá}

The traceability requirements were based on the Codex Alimentarius, under the Safe Food for Canadians Regulations Act (SFCR). Traceability documents are mandatory, in those documents, companies should be able to identify where the food was sourced, and to who is provided.

\subsubsection{Brazil}

The Brazilian Association of Supermarkets (ABRAS) launched in 2012 the initiative Food Traceability and Monitoring Program (RAMA). The RAMA program, in partnership with the GS1 Brazil, uses the GS1 128 barcode standard in order to access relevant information about a product at the same time that enables actors to manage and ensure quality in the food supply chain.

The program is focused on facilitating agents to guide the food chain to identify opportunities to improve and qualify the grower till the supermarket (Global G.A.P, 2019). 
Countries part of the European Union have been implementing traceability as an obligatory manner. Regulations may vary from country to country, in any case, they do have one same objective: to prevent and reduce any type of illness in the food supply chain of a product by the implementation of traceability in the supply network of a product.

In the specific case of developing countries, the attempts on implementing traceability, especially for SMEs, have been mostly with the use of paper registration of data, which might be useful as a first attempt to start implementing traceability in the case of small businesses, nevertheless the use of digital data registration will be necessary in the near future.

Different types of technologies can be used to implement traceability in an optimal way. Softwares, bar codes, Quick Response codes ( $\mathrm{QR}$ codes), among other instruments are the most common ones. Digital registration processes are less time consuming, they allow better and easier access to information.

Blockchain is a technology that has been related to traceability. The use of blockchain across the supply chain allows a more effective and accurate data collection and validation. Every actor in the supply chain, from producers to final consumers, are able to trace products in real-time. Businesses have to take into consideration the creation of a collaborative system recording data allowing a fast and effective response.

The lack of resources and the right infrastructure can be a challenge; however another difficulty to be able to adopt technologies is the creation of a practical and technical solution where every single actor in the supply chain would be able to use and implement, but also, can afford the prices implied.

\section{METHODS}

The development of this article has a qualitative approach. Based on a previous case study, the paper has the intention to demonstrate the impact traceability has on businesses. Nevertheless, it also presents the possible challenges at the moment of adopting new technologies for the adoption of traceability in the whole supply chain.

The main objective of this article is to corroborate the positive impact that traceability has on organizations. As mentioned before, the article is focused on a previous case study of a certified papaya producer from Tecomán, Colima exporting the products to the United States, all this, by implementing traceability in its operations.

For the development of this paper, primary and secondary data were collected. As primary data, on December 2019, a field visit was conducted to the company in Tecomán, Colima where an interview was made with the logistics and the innocuity managers inside the firm. In addition, the company was invited to answer an electronic survey to supplement the data already collected. On the other hand, information to complement the analysis was gathered from secondary data.

The methodology of this article is intended to be used as a guide for businesses to better understand and adopt a wider perspective about the implications of implementing traceability in their current processes. Based on a real case study, organizations can design and enact a traceability system adapted to their operations.

\section{RESULTS}

The use of traceability involves win-win situations, companies implement vital strategic initiatives between key actors across the supply chain, this leads to transparent processes. Transparency is an important concept these days; consumers want to know what is behind the product they are consuming. Transparency 
helps to achieve that; it allows to have better relations with suppliers, by knowing them better, creating partnerships.

\subsection{About the company}

Located in Tecomán, Colima, the studied company started operations in 2014; it is dedicated to the production and distribution of papaya. Having most of its production units certified by the National Service of Safety, Innocuity and Agri-Food Quality (Servicio Nacional de Sanidad, Inocuidad y Calidad Agroalimentaria, SENASICA by its Spanish initials), the company exports $90 \%$ of its products to the market in the United States.

As noted above, the company is mainly focused on the commercialization of the fruit to

Table 2. Bilateral trade between the USA and Mexico (papayas)

\begin{tabular}{|c|c|c|c|c|c|c|c|}
\hline \multicolumn{8}{|c|}{ PAPAYAS (PAWPAWS) FRESH } \\
\hline \multicolumn{8}{|c|}{ United States of America's imports from Mexico (Thousand USD) } \\
\hline 2012 & 2013 & 2014 & 2015 & 2016 & 2017 & 2018 & 2019 \\
\hline 66.284 & 69.284 & 89.561 & 91.848 & 97.104 & 85.272 & 86.576 & 92.351 \\
\hline \multicolumn{8}{|c|}{ United States of America's imports from world (Thousand USD) } \\
\hline 2012 & 2013 & 2014 & 2015 & 2016 & 2017 & 2018 & 2019 \\
\hline 96.97 & 102.036 & 117.555 & 129.341 & 133.593 & 121.932 & 125.222 & 129.858 \\
\hline
\end{tabular}

The adoption of traceability in the papaya company stems from the need to improve and guarantee the papaya exported is free of any contamination, especially salmonella, one of the most typical contaminants of this fruit. Implementing traceability in their processes, the papaya company is able to comply with the national and international standards to be able to distribute the fruit in both markets.

The implementation of traceability might not be a simple process since it implies changes within the organization, in particular in the business model and culture adopted. The papaya company in order to start implementing traceability increased awareness in personnel the market in the United States. One of the main risks in the papaya industry is the contamination of the fruit with salmonella, a group of around 2.300 different species of bacterias that may cause gastrointestinal illness and fever (Ross, 2018).

In the United States, there have been different salmonella outbreaks linked to Mexican papaya exporters. One of the recent salmonella outbreaks linked to the Mexican papayas was in 2017 , where the contamination of the fruit affected directly the papaya imports of the United States from Mexico, as it is shown in the following table, there was a decrease in the value of the imports in bilateral trade. about the importance of quality and safety in the processes of the fruit by having constant training creating a team culture among all the members participating.

During the interview, the logistics manager emphasizes the importance the company has on achieving and offering safe products:

We are very concerned about the quality of the product reaching the United States, the country where we export; we are worried about hygiene, quality and to keep the company in a position to be recognized in the U.S market. Collaborators, both administrative and in production, are 
very concerned about the health and taking care of those types of salmonella. - Logistics Manager (December 12, 2019).

The company during training and lectures among the employees ensures awareness of the responsibility they have as employees and as a company; makes sure they comply with the safety and hygiene rules inside the organization.
Traceability in the studied company is divided into three different types:

- Backward traceability: All the activities involved before the production process of the fruit. From suppliers to soil preparation.

- Internal traceability: Encompasses the application, cultivation, and harvest of the fruit.

- Forward traceability: From packaging the fruit to transporting it to the final destination.

Figure 6. Visual representation of the traceability system implemented by the papaya producer.

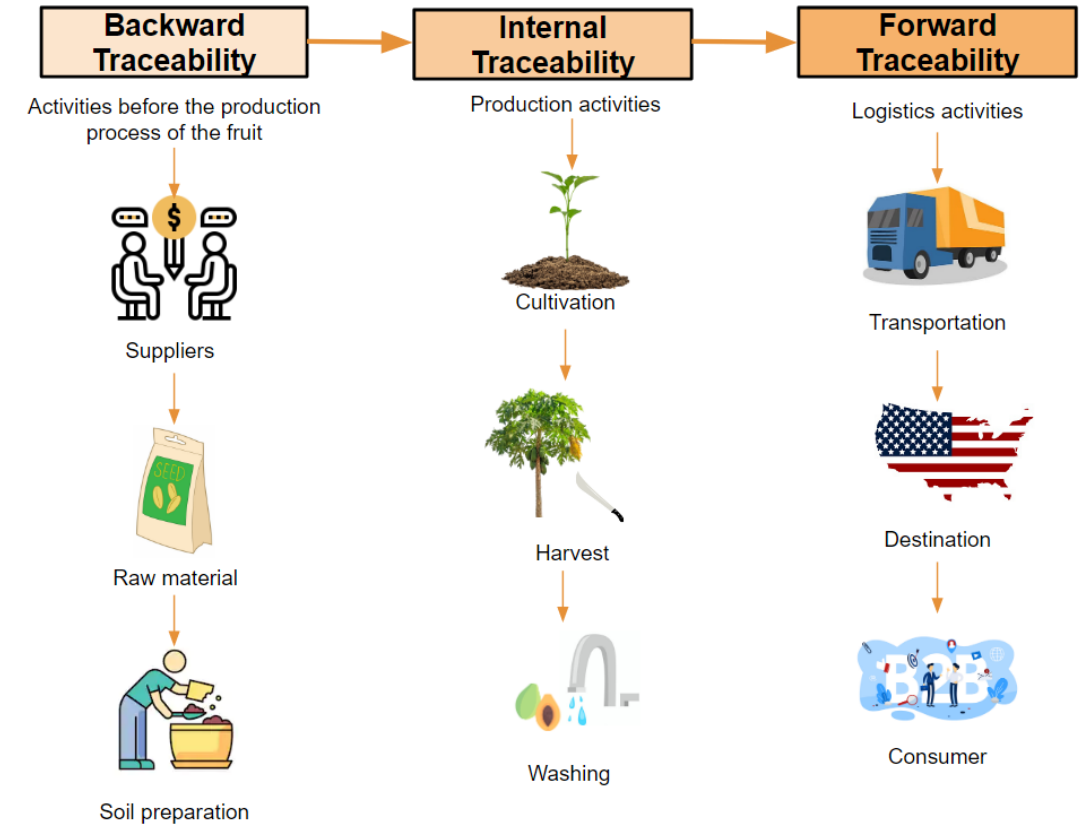

Source: Own elaboration based on data from the interview made with the managers of the company

The papaya company registers both the internal and external processes the fruit went through. For the specific case of the export processes, during the interview it was mentioned that every production unit must have a person responsible for the innocuity of that export unit:

Previously it was seen as an expense, now we see it as a necessity. - Logistics Manager (December 12, 2019).

To register the data collection from the different procedures, the company uses instruments such as a logbook, where all the relevant information regarding the manipulation of the fruit is written. The information recorded from the different instruments is used by the producers in every phase of the production process of the fruit, and if necessary, the data can be shared with regulatory authorities and clients.

Even though the papaya company has a very organized data collection system, which involves all the stages of the fruit, most of the data registration is made on paper. As technology is advancing, in the near future it would be essential to have digital registration, since it allows easier, more effective, and faster access to information. 


\subsection{Traceability complying with future market requirements}

The implementation of traceability is about talking about long-term impacts; it is about being socially responsible at the moment of increasing transparency for every actor in the supply chain, from suppliers, producers, to final consumers.

Traceability allows the structure of operations, companies are able to trace and control every single phase in the manipulation of a product during the whole supply chain. Setboonsarng, S; Sakai, J; Vancura, L (2009) states that traceability might not ensure food safety, nevertheless, it allows a faster and effective response to food safety problems, since it enables quick identification of problem sources and location in the supply chain.

Implementing traceability into a company can be a challenging but possible process. Companies have to design a traceability system that meets their specific needs, adapting it to their current operations. The majority of organizations, especially SMEs, do not have the necessary financial resources or either the right information about traceability to be able to adopt it. Nevertheless, traceability benefits outweigh the negatives.

Traceability has been gaining more importance since it works as a tool to prevent risks in the supply chain; for the food industry, traceability helps to prevent possible disease outbreaks. As mentioned before, in the specific case study made, papayas can be contaminated with Salmonella.

In the United States, the most recent salmonella outbreak was in 2019 where the exported papayas to the country were contaminated. During the interview with the personnel of the company analyzed, they were asked about the salmonella outbreak, whether the company faced any problems with it. Since traceability was already implemented in its operations, the company did not have any problem, being able to demonstrate the fruit was free of any contaminant continuing with the export process as normal.

Having traceability already implemented in its operations, the papaya producer can take advantage at the moment of entering new markets in the United States, but also in some other countries such as the ones in Europe, where traceability is a key element to guarantee high-quality products.

The papaya company is able to identify if for any reason the fruit is contaminated, in which part of the process that happens, give a solution to it, and continue with the processes as efficiently as possible. This is how traceability works. Companies applying traceability to their supply chain are able to recognize possible risks or errors in their operations.

By collecting and registering every step a product goes through, companies have better control, understanding, and adding value to their operations and products offered. Initiating with a diagnosis of the entire enterprise, identifying key areas for improvements; implementing strategies, and testing them, to finally implement the ones that better fit to their processes.

Traceability helps companies to endorse their job, without hiding any relevant information regarding the product they are offering, from production, commercialization, to final consumers. Companies can save resources and increase efficiency by going from a linear to a circular model by the implementation of traceability.

\section{CONCLUSIONS}

The use of traceability not only helps organizations to comply with non-tariff barriers, but also to decrease logistics costs, improve a company's reputation, create trust relationships, and avoid uncertainty in 
operations. The collaboration between every actor in the supply chain is important to strengthen traceability. Actors need to work together to be able to participate in a single traceability model that meets the needs of every participant in the supply chain. Traceability allows organizations to guarantee an immediate response to any possible risk in the supply chain, decreasing uncertainty, providing and adding value to the products offered.

The case study made led us to conclude three important aspects:

1. The use of traceability is a critical factor at the moment of expanding operations to new markets, especially the ones demanding strict measures to comply with quality and safety standards, all this to protect customer's health.

2. It is important for Small and Medium Enterprises (SMEs) to adopt new practices and technologies to anticipate future market requirements, all this in a competitive and globalized environment.

3. It is essential for any organization to be responsible and committed, not only socially, but also environmentally, by having transparency in their processes.

Global collaboration, driven by multistakeholder collaborative schemes, is the key to success in traceability (United Nations, 2014). For organizations adopting traceability for the first time, it is recommended to use a traceability model that better fits their operations. To create a collaborative model between every partner participating, in order to optimize processes, better communication between them, and thus, improving processes facilitating trade.

Nowadays, consumers are more aware of the product they consume: origins, materials, and the conditions under which the products were manipulated. Companies implementing a traceability system can have access to all that information, being able to respond to any situation related to the life cycle of the products they offer; and respond to any inconvenience that may occur in real-time.

The use of traceability benefits organizations at the moment of obtaining new certifications. Having a traceability system, every company is able to endorse its work, without hiding any relevant information related to every phase in its whole supply chain, having traceable products and transparent processes, being able to prove that in real-time with the use of technology. As mentioned in previous sections, organizations may face difficulties in adapting traceability, mainly for the lack of financial resources, but also the lack of knowledge about this relevant topic.

The regulations or programs enforcing the use of traceability have been increasing their demand in many countries. Developing and developed countries are in a better position to adopt these practices. Analyzing the case of the papaya producer, the principal driver for the implementation of traceability was the concern about quality and hygiene in the manipulation of the fruit along with the mandatory regulations demanded by the neighboring country.

The studied company understands and shares the importance and benefits of traceability. One of the main findings of the article is that most small businesses do not consider technology or data digitization as a fundamental element to implement traceability, due to the fact that paper registration is simpler for the members to use as well as it helps them to fulfill and collect all the necessary data being able, in the case of the papaya producer, to export to the market in the United States.

Implementing traceability inside a company involves investments of time, skills, and capabilities. Corporations must be open to 
new ideas, abandoning traditional focus by the adoption of wider overviews. Governments play an important role in these tasks, as they are key factors to stimulate innovation and support those activities for different companies by enacting norms and rules to operate. By having the right tools for action, companies can be driven for success, achieving their goals and creating value for the long-term.

Another important aspect of traceability to make it function is the creation of a team culture where all the personnel inside a company understand, are committed, and engaged in learning and make good changes, working on the same line. Businesses would understand better how their supply chain works, they would have detailed information that can be used for better decisions inside the company, and final consumers will have the certainty they are consuming only high-quality products.

These days, any organization, in any industry, must be able to verify every stage in its supply chain. By having traceable products, companies implementing traceability are able to identify in which part of the processes there might be any possible risk or error, being able to prevent any failure in the supply chain. 


\section{REFERENCES}

International Trade Centre (2015). Traceability in Food and Agricultural Products. Retrieved from ITC:

http://www.intracen.org/uploadedFiles/intracenorg/Content/Exporters/Exporting_Better/Quali ty_Management/Redesign/EQM\%20Bulletin\%2091-

2015_Traceability_FINAL\%2014Oct15_web.pdf

Food and Agriculture Organization of the United Nations (2017). Food Traceability Guidance. Retrieved from FAO: http://www.fao.org/3/a-i7665e.pdf

Ekon (June 30, 2017). Tipos de trazabilidad y su relación con la tecnología. Retrieved from Ekon: https://www.ekon.es/blog/tipos-trazabilidad-tecnologia/

GS1 (August, 2017). GS1 Global Traceability Standard. Retrieved from GS1: https://www.gs1.org/sites/default/files/docs/traceability/GS1_Global_Traceability_Standard_i 2.pdf

GS1 (May, 2008). What is GS1? An overview May 2008. Retrieved from GS1: https://www.gs1.org/sites/default/files/docs/what_is_gs1.pdf

United Nations (April, 2014). A Guide to Traceability: A practical approach to advanced sustainability in global supply chains. Retrieved from BSR: https://www.bsr.org/reports/BSR_UNGC_Guide_to_Traceability.pdf

Setboonsarng, S; Sakai, J; Vancura, L (May, 2009). Food safety and ICT traceability systems: Lessons from Japan for developing countries. Retrieved from Econstor: https://www.econstor.eu/bitstream/10419/53743/1/604642695.pdf

European Parliament (February 12, 2015). Circular economy: definition, importance, and benefits. Retrieved from European Parliament: https://www.europarl.europa.eu/news/en/headlines/economy/20151201STO05603/circulareconomy-definition-importance-and-benefi

Global G.A.P (September 26, 2019). Brazilian Association of Supermarkets (ABRAS) joins GLOBAL G.A.P. Retrieved from Global G.A.P: https://www.globalgap.org/uk_en/mediaevents/news/articles/Brazilian-Association-of-Supermarkets-ABRAS-Joins-GLOBALG.A.P./

EUR-Lex (January 28, 2002). Regulation (EC) No 178/2002 of the European Parliament and of the Council. Retrieved from EUR-Lex: https://eur-lex.europa.eu/legalcontent/EN/TXT/?uri=CELEX\%3A32002R0178

FDA (January 4, 2020). Food Safety Modernization Act (FSMA). Retrieved from FDA: https://www.fda.gov/food/guidance-regulation-food-and-dietary-supplements/food-safetymodernization-act-fsma

Food Standards (February, 2019). Standard 3.2.2 - Food Safety Practices and General Requirements. Retrieved from Food Standards: https://www.foodstandards.gov.au/industry/safetystandards/safetypractices/pages/default.aspx \#: :text=2\%20\%E2\%80\%93\%20Food\%20Safety\%20Practices\%20and\%20General\%20Requ irements,-Page $\% 20$ Content\&text=and\%20General\%20Requirements,Standard\%203.2.,disposal\%20and\%20recall\%20of\%20food.

Government of Canada (March 26, 2020). Regulatory requirements: Traceability. Retrieved from Government of Canada: https://www.inspection.gc.ca/food-safety-forindustry/traceability/traceability/eng/1522294721005/1522294781171

Buso, G (2019). Traceability in Brazil's fruit and vegetable industry. Retrieved from PMA: https://www.pma.com/content/articles/traceability-in-brazils-fruit-and-vegetable-industry

Ross, R (November 7, 2018). What is Salmonella?. Retrieved from Live Science: https://www.livescience.com/64031-salmonella.html 